\title{
Percepção dos professores da rede regular de ensino sobre os problemas visuais e a inclusão de alunos com baixa visão
}

\author{
Teachers' perception about vision illness \\ and the inclusion of low vision students
}

Aparecida Tapia Maruyama', Paulo Ricardo Souza Sampaio², José Ricardo Lima Rehder

\section{ResUMO}

Objetivo: Verificar e analisar o conhecimento a respeito dos problemas visuais e do tema baixa visão entre os professores da rede regular de ensino, justificando a importância do pedagogo especializado como elo de ligação entre o médico oftalmologista e a escola. Métodos: Survey descritivo e documental, onde foi aplicado um questionário a 230 professores que atuam na rede regular de ensino, de primeira a quarta série do Ensino Fundamental I da cidade de Santo André (SP). Resultados: Foram respondidos $123(53,5 \%)$ questionários. Quando perguntados se tinham recebido alguma orientação técnica a respeito de como lidar com alunos com baixa visão $21,1 \%$ respondeu afirmativamente, $95,9 \%$ acredita que o aluno com baixa visão tem dificuldades para aprender e $43,9 \%$ não sabe como encaminhar a serviço oftalmológico especializado. Conclusão: A falta de conhecimentos técnicos a respeito de como atuar diante do aluno com baixa visão justifica a importância do pedagogo especializado em baixa visão e cegueira (Visopedagogo), como elemento imprescindível para a educação inclusiva, na equipe multidisciplinar do médico Oftalmologista.

Descritores: Baixa visão; Cegueira; Saúde escolar; Conhecimentos, atitudes e prática em saúde; Questionários; Ensino fundamental e médio

\footnotetext{
'Pedagoga, Pós-graduanda strictu-sensu da Faculdade de Medicina do ABC - FMABC - Santo André (SP), Brasil;

${ }^{2}$ Chefe do Setor de Visão Subnormal da Disciplina de Oftalmologia - Faculdade de Medicina do ABC - FMABC - Santo André (SP), Brasil;

${ }^{3}$ Professor Titular de Oftalmologia da Faculdade de Medicina do ABC - FMABC - Santo André (SP), Brasil.
}

Trabalho realizado como dissertação de Mestrado da Faculdade de Medicina do ABC - FMABC - Santo André (SP), Brasil.

Recebido para publicação em: 9/3/2009 - Aceito para publicação em 25/4/2009 


\section{INTRODUÇÃO}

$\mathbf{O}$ Decreto n. ${ }^{\circ} 3.298$, de 20 de dezembro de $1999^{(1)}$, dispõe sobre a Política Nacional para a Integração da Pessoa Portadora de Deficiência, garantindo o acesso de deficientes à rede escolar convencional, pública ou particular. Mas, a frase mais ouvida pelos pais até o ano de 2005 foi: "Nós não temos profissionais adequados para trabalhar com seu filho!"*.

Desde então o número de alunos com necessidades especiais está aumentando nas salas de aula do Brasil. E esse crescimento da chamada educação inclusiva pode ser notado na rede pública de ensino **.

Para que ocorra inclusão escolar do aluno com baixa visão, com critério, é importante que ele vivencie experiências significativas, tenha sua autoestima trabalhada e fortalecida através de um trabalho pedagógico onde consiga lidar com seus limites, frustrações e capacidades, além de proporcionar-lhe o exercício consciente da cidadania ${ }^{(2-4)}$.

O objetivo deste trabalho é verificar e analisar o conhecimento a respeito dos problemas visuais e do tema baixa visão entre os professores da rede regular de ensino, justificando a importância do pedagogo especializado como elo de ligação entre o médico oftalmologista e a escola. O pedagogo especializado em baixa visão tem papel importante nesse processo, pois esclarece a avaliação clínico-funcional ou seja os dados quantitativos e qualitativos do exame ocular realizado pelo médico, orientando os pais, os professores e a equipe escolar onde o aluno estuda quanto às dificuldades oculares e a utilização de auxílios ópticos, não ópticos e tecnológicos ${ }^{(2,5)}$.

Através deste estudo será possível compreender a necessidade de incluir os custos gerados por este profissional no sistema de saúde pública e sistemas de apurações de despesas de clínicas oftalmológicas privadas, planejando e viabilizando medidas econômicas que gerem condições assistenciais adequadas a essa população.

\section{Métodos}

O tipo de estudo utilizado foi o survey descritivo e documental, onde foi aplicado um questionário como técnica de coleta de dados a 230 professores que atuam na rede regular de ensino, de primeira a quarta série do ensino fundamental I da cidade de Santo André (SP).

Como variáveis dependentes foram pesquisados: reconhecimento de baixa visão, medida de acuidade visual, como o aluno utiliza o resíduo visual, auxílios ópticos - uso e restrições, informática adaptada, braille e sorobã.
As variáveis independentes assumiram aspecto somente descritivo.

\section{Resultados}

Foram entregues 230 questionários a professores de escolas da rede pública municipal de Santo André (SP) e, deste total, foram devolvidos devidamente respondidos $123(53,5 \%)$.

A média da idade dos profissionais foi de 38 anos, variando de 21 a 61 anos de idade.

A média geral de tempo de magistério foi de 10 anos.

Quando perguntados se tinham recebido alguma orientação técnica a respeito de como lidar com alunos com baixa visão somente $21,1 \%$ dos entrevistados respondeu afirmativamente.

Do total, $73,2 \%$ não sabe o que é ambliopia, $68,3 \%$ acha que a criança deficiente visual estraga a visão se ler ou assistir televisão muito próximo, 95,9\% acredita que o aluno com baixa visão tem dificuldades para aprender e $43,9 \%$ não sabe como encaminhar a criança a serviço oftalmológico especializado.

\section{Discussão}

Apesar do aumento crescente do número de alunos com necessidades especiais nas salas de aulas, o professor ainda mostra dificuldade para ensiná-lo e até mesmo para onde encaminhá-lo.

Poucos são aqueles com as orientações técnicas necessárias sobre deficiência visual, como mostra o estudo. Também, o médico oftalmologista, atarefado no dia a dia com seus pacientes, não encontra tempo e espaço para dialogar por longos períodos com os professores que atuam com o deficiente visual. Esta relação tornase, portanto, conflituosa.

Neste processo de transição, a figura do pedagogo especializado em problemas visuais (e, já que são aceitas as especialidades de psicopedagogia e de neuropedagogia porque não denominá-lo visopedagogo) parece adequada.

Este profissional com seus conhecimentos a respeito de modelos de aprendizagem, técnicas de ensino, didática, baixa visão, braille, cegueira, auxílios ópticos e informática vincula áreas do saber tornando-se importante para o aluno, para o paciente, para o médico, para a família, para a escola e para a sociedade, conquanto também é o responsável pela inserção social e de mercado de trabalho do deficiente visual.

\footnotetext{
* Jornal Nacional. Educação para deficientes. São Paulo: TV Globo; 2005 Set 19

** Jornal Nacional. Número de alunos especiais aumenta nas escolas. São Paulo: TV Globo; 2009 Fev 16.

Rev Bras Oftalmol. 2009; 68 (2): 73-5
} 
O mercado brasileiro dispõe deste pedagogo. São formados, tanto em nível de pós-graduação lato-sensu como de strictu-sensu nas melhores instituições de ensino universitário no Brasil. Conseguem, portanto, ser entendidos tanto pelo médico como pelo professor do ensino fundamental. Sua existência precisa ser divulgada e valorizada tanto pelas escolas como pelo oftalmologista.

É de suma importância incluir os custos gerados por este profissional no sistema de saúde pública e sistemas de apurações de despesas de clínicas oftalmológicas privadas, planejando e viabilizando medidas econômicas que gerem condições assistenciais adequadas para população deficiente visual.

\section{ConClusão}

A (ainda) falta de conhecimentos técnicos adequados a respeito de como atuar diante do aluno com baixa visão e cegueira justifica a importância do pedagogo especializado em baixa visão (visopedagogo), como elemento imprescindível para a educação inclusiva, na equipe multidisciplinar do médico oftalmologista.

\section{Abstract}

Objective: The object of this study was recognized the knowledge about vision illness and low vision between teachers and the relationship between ophthalmologists and school. Methods: Descriptive survey, including questions to 230 teachers who were working at fundamentary I schools, in Santo André city - SP. Results: Hundred twenty-three questions (53,5\%) were answered. When the teachers were asked about some training on how to deal with students vision illness; $21,1 \%$ answered confirmed the training; $95,9 \%$ believe that the students have difficult learning and 43,9\% don't know how to deal and indicate a doctor appointment. Conclusion: The right technical knowledge about the students vision illness, justify the necessity of a pedagogical working on blindness and low vision to adapted and including the students, in the multidiscipline ophthalmologist doctor.

Keywords: Vision, low; Blindness; School health; Health knowledge, attitudes, practice; Questionnaires; Education, primary and secondary

\section{REFERÊNCIAS}

1. Brasil. Ministério da Educação. Decreto n. ${ }^{\circ} 3.298$, de 20 de dezembro de 1999. Regulamenta a Lei n. ${ }^{\circ} 7.853$, de 24 de outubro de 1989, dispõe sobre a política nacional para a integração da pessoa portadora de deficiência, consolida as normas de proteção, e dá outras providências. Legislação de educação especial na [Internet]. Brasília (DF); 1999 [citado em 2009 Fev 26]. [18p]. Disponível em: http://portal.mec.gov.br/arquivos/pdf/decreto3298.pdf

2. Masini EFS, Gasparetto MERF, organizador. Visão subnormal: um enfoque educacional. São Paulo: Vetor; 2007.

3. Brasil. Ministério da Educação. Secretaria de Educação Fundamental. Secretaria de Educação Especial. Parâmetros curriculares nacionais: adaptações curriculares - estratégias para a educação de alunos com necessidades educacionais especiais. Brasília (DF): MEC/SEF/SEESP; 1999.

4. Ribeiro MLS, Baumel RCRC, organizador. Educação especial: do querer ao poder fazer. São Paulo: Avercamp; 2003.

5. Masini EFS, organizador. A pessoa com deficiência visual: um livro para educadores. São Paulo: Vetor; 2007.

6. Corsi, MGF. Visão subnormal: intervenção planejada. São Paulo: M.G.F. Corsi; 2001.

\author{
ENDEREÇO PARA CORRESPONDÊNCIA: \\ Aparecida Tapia Maruyama \\ Rua Benjamin Reis no 56 - apto 31 - Bloco 16 \\ CEP 03178-060 - São Paulo - SP \\ Telefax : (11) 2601-7021 \\ E-mail: maruyamatapia@uol.com.br
}

